\title{
Anorectal malformation with didelphys uterus: Extremely rare anomaly and successful neoanal sphincter reconstruction with gracilis muscle flap
}

\author{
Chairat Burusapat ${ }^{1}$, Natthawoot Hongkarnjanakul ${ }^{1}$, Nutthapong Wanichjaroen ${ }^{1}$, \\ Sakchai Panitwong ${ }^{2}$, Jiraporn Sangkaewsuntisuk ${ }^{3}$, Chinakrit Boonya-ussadorn ${ }^{3}$ \\ ${ }^{1}$ Division of Plastic and Reconstructive Surgery, Department of Surgery, Phramongkutklao Hospital, Bangkok; ${ }^{2}$ Division of Reproductive \\ Medicine, Department of Obstetrics and Gynecology and ${ }^{3}$ Division of Colorectal Surgery, Department of Surgery, Phramongkutklao Hospital, \\ Phramongkutklao College of Medicine, Bangkok, Thailand
}

\begin{abstract}
Anorectal malformation or imperforate anus is a congenital anomaly of rectum and anus. Mullerian duct anomalies are abnormal development of uterus, cervix, and vagina. Imperforate anus with double uterus is extremely rare and cannot explain by normal embryologic development. Moreover, guideline in treatment is inconclusive. We report an extremely rare case of a young adult female who presented with recurrent pelvic inflammatory disease caused by rectovaginal fistula in congenital imperforate anus and didelphys uterus, and successfully neoanal reconstruction with gracilis muscle flap. Aims for treatment are closed rectovaginal fistula, and anal sphincter reconstruction. To our best knowledge, the imperforate anus with double uterus is extremely rare anomaly. Furthermore, successfully anal sphincter reconstruction with functional gracilis muscle in the imperforate anus with double uterus has never been reported in English literature.
\end{abstract}

Keywords Anorectal malformation / Didelphys uterus / Rectovaginal fistula / Gracilis muscle pISSN: 2234-6163 • elSSN: 2234-6171 • https://doi.org/10.5999/aps.2019.01032 • Arch Plast Surg 2020;47:272-276

\author{
Correspondence: Chairat Burusapat \\ Division of Plastic and Reconstructive \\ Surgery, Department of Surgery, \\ Phramongkutklao Hospital, 315 \\ Ratchawithi Road, Thung Phayathai, \\ Ratchathewi, Bangkok 10400, \\ Thailand \\ Tel: +66-2354-7600 \\ Fax: +66-25-805958 \\ E-mail: pataranat@hotmail.com
}

\section{INTRODUCTION}

Anorectal malformation or imperforate anus is a congenital anomaly of rectum and anus. The abnormalities are including absence or malposition of an anal opening, or fistula between intestine and urinary system, or intestine and vagina. Mullerian duct anomalies (MDAs) are abnormal development of uterus, cervix, and vagina before 22 weeks in gestation. A didelphys uterus, or double uterus, is one of the least common of MDAs [1].

However, imperforate anus with double uterus is extremely rare anomaly. Moreover, the guideline in treatment is inconclusive. We present an extremely rare case of a young adult female who presented with recurrent pelvic inflammatory disease (PID) caused by rectovaginal fistula in congenital imperforate anus and double uterus, and successfully neoanal reconstruction with gracilis muscle flap which has not previously been reported in English literature. The study was approved by the Institutional Review Board of Royal Thai Army Medical Department (IRB No. s060h/62_exp) and written informed consent was obtained. 


\section{CASE}

A 31-year-old female presented with intermittent fever and pelvic pain, she had been treated as recurrent PID for 5 years and improved with antibiotic. She was born with imperforated anus and temporary colostomy was performed since birth. When she was 2 years old, she was operated for take down colostomy and anal reconstruction. However, she had rectovaginal fistula and suffered from fecal incontinent with some fecal pass through vagina since then. The physical examination showed rectovaginal fistula $2 \times 2 \mathrm{~cm}$. in diameter with $1 \mathrm{~cm}$ from anal verge $(\mathrm{AV})$ and

\section{Fig. 1. Preoperative anomaly}

The physical examination showed anorectal malformation and rectovaginal fistula.

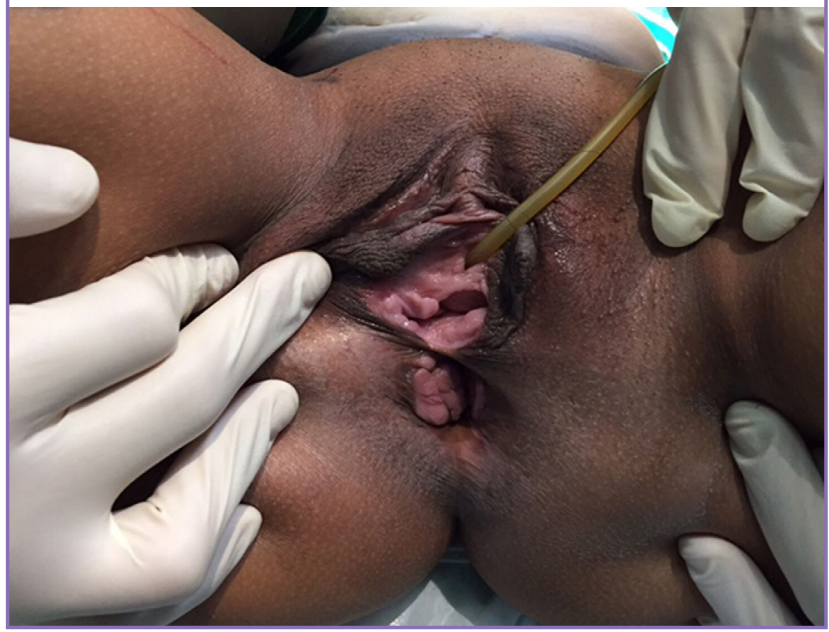

Fig. 2. Intraoperative image of double uterus

Intraoperative finding showed right uterus (white arrow), left uterus (yellow arrow), left hydrosalpinx and left ovarian cyst.

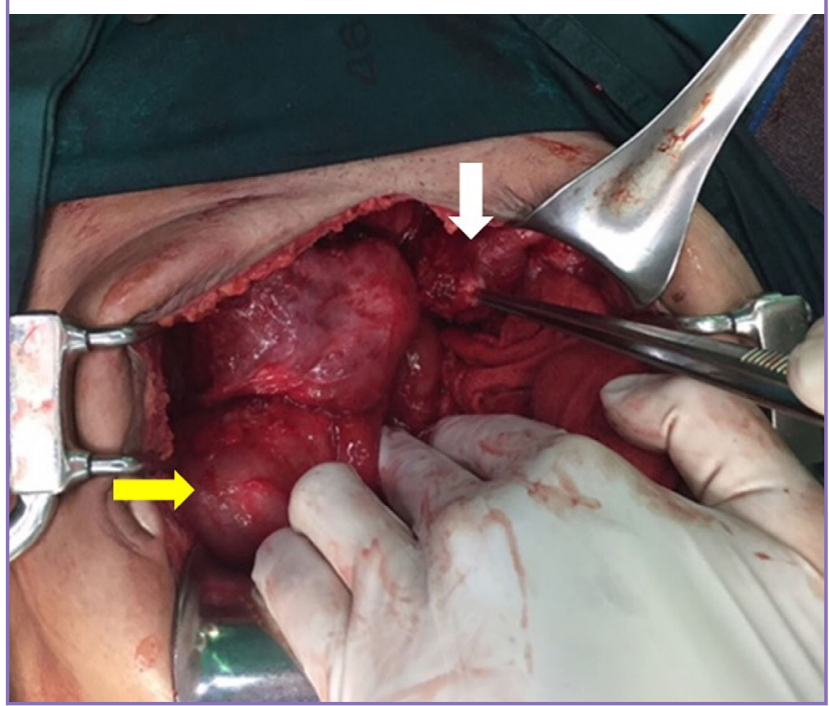

abnormal outpouching lesion at $7 \mathrm{~cm}$ from $\mathrm{AV}$ (Fig. 1). Colonoscopy showed rectovaginal fistula with blind anal pouch. Biopsy was performed at blind anal pouch, vagina and fistula site. The pathologic was reported "blind pouch" as non-keratinizing squamous mucosa with negative for dysplasia, neoplasm and inflammation.

Magnetic resonance imaging demonstrated double uterus, double cervix with common vaginal at lower part. There were two rectovaginal fistulas tract, the first one was rectovaginal fistula at lower part which showed communication of the anterior rectum and posterior right-side vagina, another fistula tract showed communication between rectum and right-side vagina. Moderate amount of air in both sides of the vaginal canal and at lower endometrial cavity and endocervix of right-side uterus was demonstrated. Normal left ovary and both kidneys. Right ovary was not observed.

The operation was performed on lithotomy position under general anesthesia. The rectovaginal fistula, double uterus (with one cervix on left uterus), left hydrosalpinx and left ovarian cyst were identified (Figs. 2, 3). Left salpingectomy, left partial ovarian cystectomy, right hysterectomy and colostomy were performed. The gracilis myocutaneous flap was harvested on the right leg, skin island was designed and preserved to be the perineal skin and monitoring flap, the perforator was identified and preserved, the flap was turned-around anal canal, and distal part of gracilis muscle was fixed to periosteum over the tuberosity of the left ischial tuberosity. The rectovaginal fistula was closed and neoanal sphincter reconstruction with gracilis myocutaneous flap was performed (Figs. 4, 5). No postoperative complica-

\section{Fig. 3. Diagram of anomaly}

Illustrative diagram of double uterus, double vagina, left hydrosalpinx and two rectovaginal fistulas.

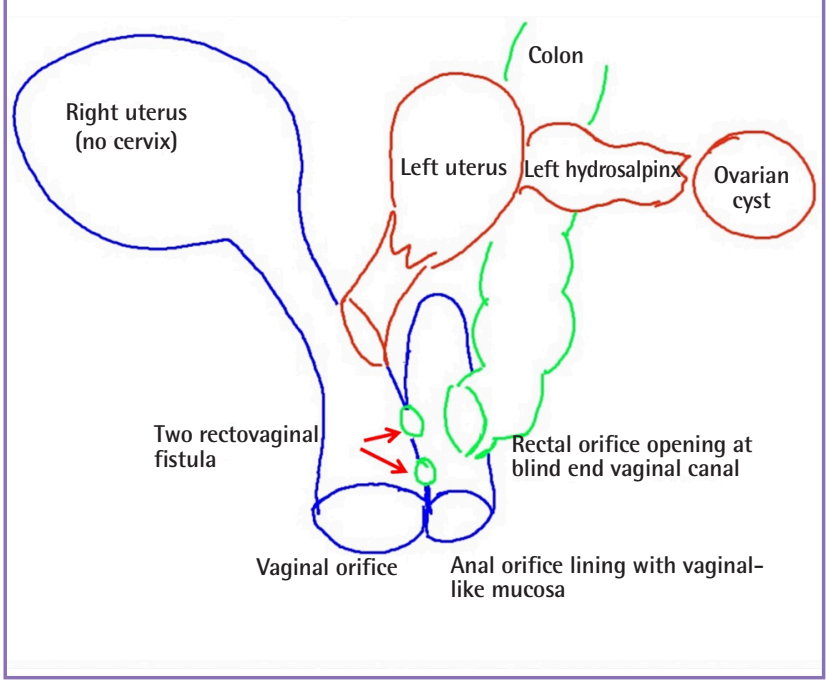


Fig. 4. Neoanal sphincter reconstruction with gracilis muscle flap

(A) Gracilis myocutaneous flap was elevated, the perforator was identified and preserved (blue arrow) and (B) skin paddle for perineal body (white arrow) and gracilis muscle for anal sphincter (yellow arrow) was performed.

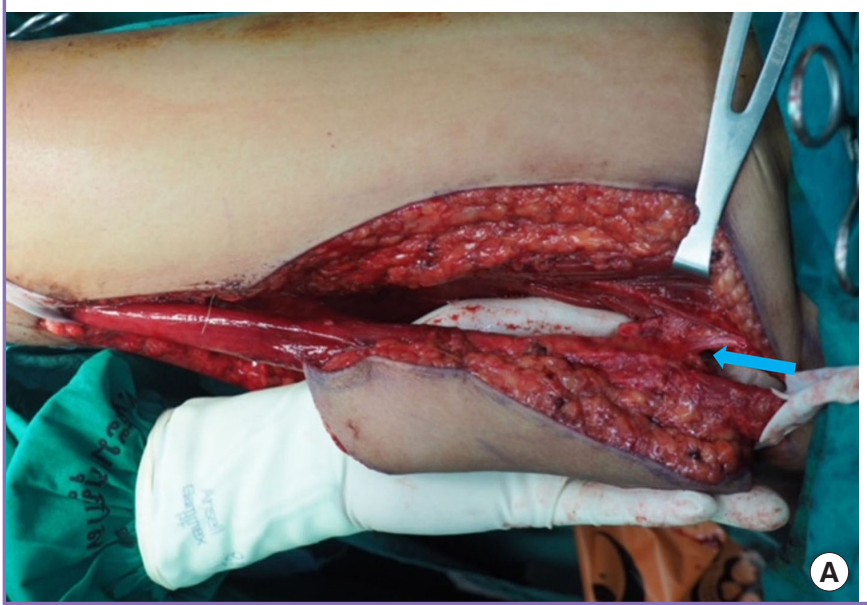

Fig. 5. Diagram of operation

Illustration of neoanal sphincter reconstruction with gracilis muscle flap;(1) vagina; (2) anus; (3) gracilis flap was turned-around anal canal and distal part of gracilis muscle was fixed to periosteum over the tuberosity of the left ischial tuberosity (blue cross sign), and skin island for perineal body and monitoring flap was designed (black dot circle).

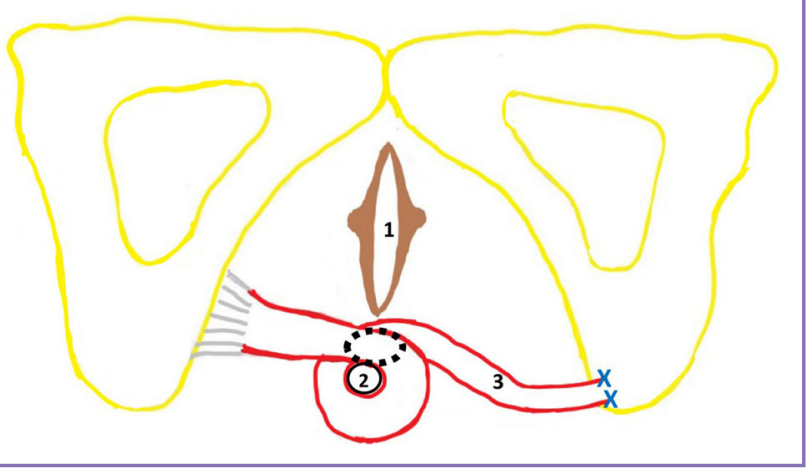

Fig. 6. An immediate postoperative photograph

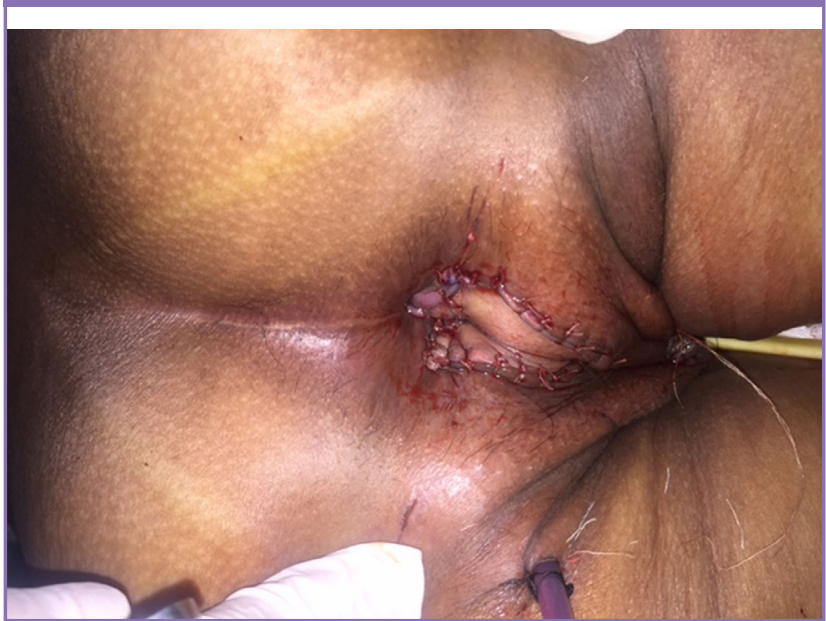

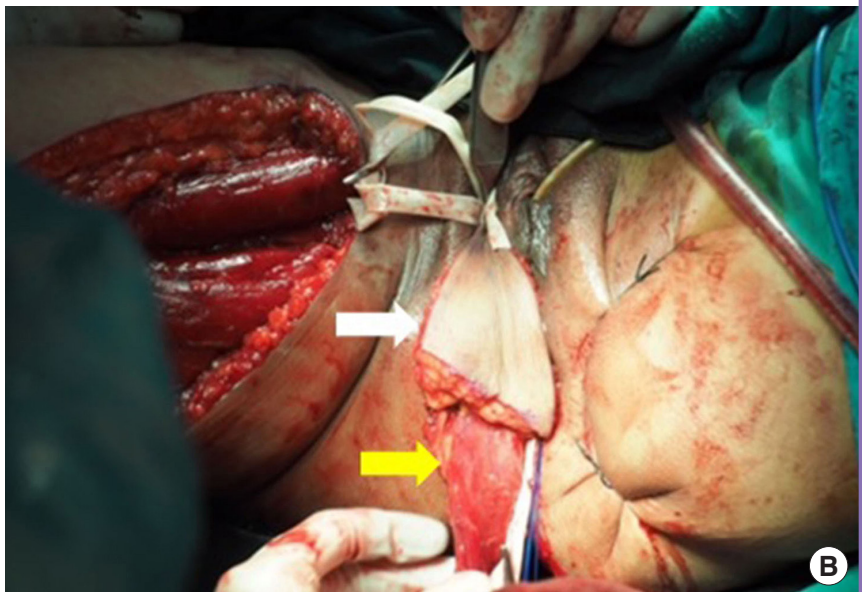

Fig. 7. Photograph at follow-up on postoperative 6 months

Skin island of gracilis myocutaneous flap at perineum.

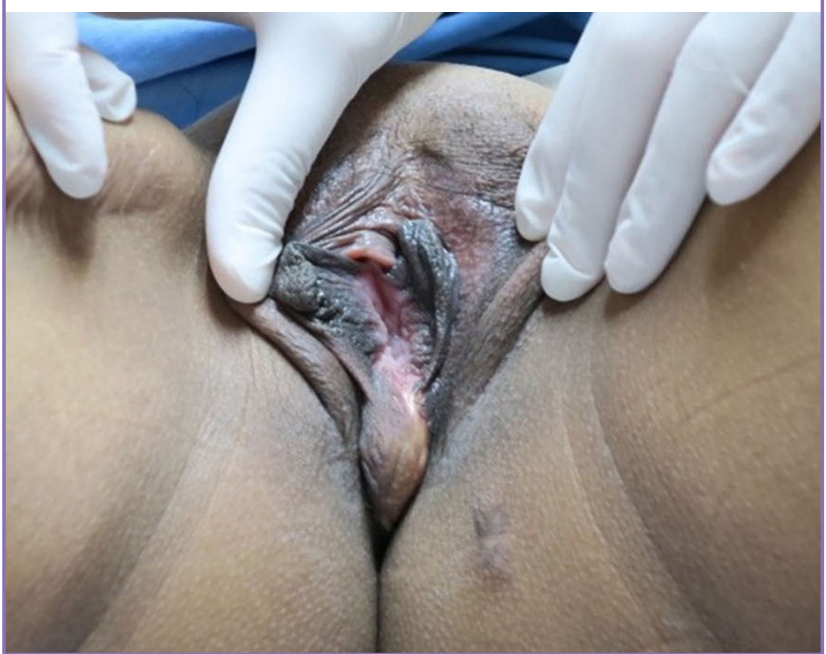

tion was found (Figs. 6, 7). Histopathology of the uterus showed adenomyosis, inactive endometrium, acute and chronic cervicitis and consistent with clinical diagnosis of didelphys uterus. The sphincter was controlled by hip adduct and slightly medially rotate the hip and knee. The colostomy was taken down without any complication.

\section{DISCUSSION}

Mullerian duct anomaly can result in abnormalities of uterus, cervix, and vagina. Didelphys uterus, or double uterus, is failure fusion of the paired Mullerian ducts between 12th and 16th weeks of gestation, resulting in duplication of uterus and cervix, with or without a vaginal septum [2]. A didelphys uterus is a 
very rare Mullerian duct anomaly in comparison to other anomalies [1]. The diagnosis is usually delayed after menarche [3].

Previous reports of atypical didelphys uterus such as didelphys uterus with bilateral cervical agenesis [4], didelphys uterus with one cervix [5], septate uterus with double cervix and a longitudinal vaginal septum [6]. All of them reported the double uterus without imperforate anus. Complications of these anomalies are hydrosalpinx, pyosalpinx, hematocolpos, tubo-ovarian abscess, and endometriosis. Early diagnosis and closed follow-up of patients with MDAs is important to avoid potential future complications [7].

There were only few reports about the anorectal malformation and double uterus. Previous reports were usually demonstrated in infant and in autopsy from terminated pregnancy. Arnone et al. [8] reported the infant was born with single introitus, imperforate anus, didelphys uterus, duplicated cervix and vagina, and accessory limb and coccyx. Multiple surgeries were performed for correct the anomaly. Witters et al. [9] reported the intrauterine ultrasound at 30 weeks showed a hydrometrocolpos with didelphys uterus, a single umbilical artery, mild ascites and growth on the 10th centile. Pathological examination after pregnancy termination revealed low vaginal atresia with didelphys uterus, anal atresia with rectovaginal fistula and a normal urinary tract. Hall et al. [10] revealed the imperforate anus with genital tract anomaly and found eight cases $(11.11 \%)$ of didelphys uterus combined with imperforate anus. However, his report did not demonstrate the severity of imperforate anus and detail of the patients. The extremely rare anomaly of anorectal malformation or imperforate anus with double uterus is not explained by normal embryologic development. Our patient presented with recurrent PID caused by rectovaginal fistula in congenital imperforate anus and double uterus, and successfully anal reconstruction with gracilis muscle flap that has never been reported.

Matta et al. [11] reported a 3-year-old girl with double vagina, double urethra, double sacrum, double ureters on the right side, multiple vertebral anomalies and anorectal malformation. Chadha et al. [12] reported a girl with congenital pouch colon, double uterus with septate vagina, and a cloacal anomaly. However, our patient is not defined as cloaca malformation because she has normal urinary system. Didelphys uterus is a very rare Mullerian duct anomaly. When a didelphys uterus is diagnosed, renal anomalies should be investigated.

The reports of didelphys uterus are limited at the present time. More studies are necessary to determine the reproductive outcomes and better care for the patients. It is extremely important to establish an accurate neonatal diagnosis, and prevent the complication. Aims for treatment in this patient are closed rectovaginal fistula, prevent recurrent PID and anal sphincter re- construction. Gracilis muscle flap has been used as perineal reconstruction. The muscle may be transposed as a function muscle for rectal sphincter and vaginal reconstruction, mostly from cancer, trauma or Fournier's gangrene, rarely reported in congenital defect. Pickrell et al. [13] reported the anal sphincter with gracilis muscle flap for anal incontinence in children with spina bifida. Kalisman and Sharzer [14] reported the anal sphincter and perineal skin resurfacing with gracilis myocutaneous flap in a 60-year-old woman with radiation proctitis and perineal radiodermatitis.

To our best knowledge, the imperforate anus with double uterus is extremely rare anomaly. Furthermore, successfully anal sphincter reconstruction with functional gracilis muscle in the imperforate anus with double uterus has never been reported in English literature.

\section{NOTES}

\section{Conflict of interest}

No potential conflict of interest relevant to this article was reported.

\section{Ethical approval}

The study was approved by the Institutional Review Board of Royal Thai Army Medical Department (IRB No. s060h/62 exp) and performed in accordance with the principles of the Declaration of Helsinki. Written informed consent was obtained.

\section{Patient consent}

The patient provided written informed consent for the publication and the use of her images.

\section{Author contribution}

Conceptualization: C Burusapat. Data collection and literature review: N Hongkarnjanakul, N Wanichjaroen. Methodology: C Burusapat, S Panitwong, J Sangkaewsuntisuk, C Boonya-ussadorn. Writing-original draft: C Burusapat, $\mathrm{N}$ Wanichjaroen. Writing-review \& editing: C Burusapat, N Wanichjaroen. Approval of final manuscript: all authors.

\section{ORCID}

Chairat Burusapat https://orcid.org/0000-0002-2705-4215 Natthawoot Hongkarnjanakul

Nutthapong Wanichjaroen

https://orcid.org/0000-0003-1629-1319

https://orcid.org/0000-0003-4255-4696

Sakchai Panitwong https://orcid.org/0000-0002-0096-2424 
Jiraporn Sangkaewsuntisuk

https://orcid.org/0000-0002-7871-1828

Chinakrit Boonya-ussadorn

$$
\text { https://orcid.org/0000-0002-4759-5916 }
$$

\section{REFERENCES}

1. Rezai S, Bisram P, Lora Alcantara I, et al. Didelphys uterus: a case report and review of the literature. Case Rep Obstet Gynecol 2015;2015:865821.

2. Ades A, Hong P. Successful laparoscopic transabdominal cerclage in uterus didelphys. BMJ Case Rep 2015;2015: bcr2015212977.

3. Varras M, Akrivis Ch, Karadaglis S, et al. Uterus didelphys with blind hemivagina and ipsilateral renal agenesis complicated by pyocolpos and presenting as acute abdomen 11 years after menarche: presentation of a rare case with review of the literature. Clin Exp Obstet Gynecol 2008;35:156-60.

4. Arnold KC, Thai TC, Craig LB. Uterine didelphys with bilateral cervical agenesis in a 15-year-old girl. J Pediatr Adolesc Gynecol 2018;31:64-6.

5. Verma ML, Singh U, Ghosh I, et al. Uterine didelphys with one cervix obscured by blind hemivagina: a lesson in rarity. BMJ Case Rep 2018;2018:bcr-2018-224994.

6. Pavone ME, King JA, Vlahos N. Septate uterus with cervical duplication and a longitudinal vaginal septum: a müllerian anomaly without a classification. Fertil Steril 2006;85:494. e9-e10.

7. Mollitt DL, Schullinger JN, Santulli TV, et al. Complications at menarche of urogenital sinus with associated anorectal malformations. J Pediatr Surg 1981;16:349-52.

8. Arnone K, Cloutier J, Bolduc S. Persistent cloaca and partial caudal duplication: a case report. Urology 2011;78:431-3.

9. Witters I, Meylaerts L, Peeters H, et al. Fetal hydrometrocolpos, uterus didelphys with low vaginal and anal atresia: difficulties in differentiation from a complex cloacal malformation: a case report. Genet Couns 2012;23:513-7.

10. Hall R, Fleming S, Gysler M, et al. The genital tract in female children with imperforate anus. Am J Obstet Gynecol 1985;151:169-71.

11. Matta H, Nawaz A, Jacobsz AW, et al. A rare association of urogenital duplication and anorectal malformation.J Pediatr Surg 2002;37:1623-5.

12. Chadha R, Puri M, Saxena R, et al. Congenital pouch colon in a girl associated with bilateral atresia of cervix uteri and uterus didelphys. J Indian Assoc Pediatr Surg 2013;18:81-3.

13. Pickrell KL, Broadbent TR, Masters FW, et al. Construction of a rectal sphincter and restoration of anal continence by transplanting the gracilis muscle; a report of four cases in children. Ann Surg 1952;135:853-62.

14. Kalisman M, Sharzer LA. Anal sphincter reconstruction and perineal resurfacing with a gracilis myocutaneous flap. Dis Colon Rectum 1981;24:529-31. 